\title{
Surface modification of starch based blends using potassium permanganate-nitric acid system and its effect on the adhesion and proliferation of osteoblast-like cells
}

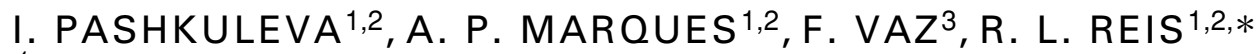 \\ ${ }^{1}$ Department of Polymer Engineering, University of Minho, Campus de Azurém, \\ 4800-058 Guimarães, Portugal \\ 23B's Research Group-Biomaterials, Biodegradables and Biomimetics, \\ University of Minho, Campus de Gualtar, 4710-057 Braga, Portugal \\ ${ }^{3}$ Department of Physics, University of Minho, Campus de Azurém, \\ 4800-058 Guimarães, Portugal \\ E-mail:rgreis@dep.uminho.pt
}

The surface modification of three starch based polymeric biomaterials, using a $\mathrm{KMnO}_{4} / \mathrm{NHO}_{3}$ oxidizing system, and the effect of that modification on the osteoblastic cell adhesion has been investigated. The rationale of this work is as follows-starch based polymers have been proposed for use as tissue engineering scaffolds in several publications. It is known that in biodegradable systems it is quite difficult to have both cell adhesion and proliferation. Starch based polymers have shown to perform better than poly-lactic acid based materials but there is still room for improvement. This particular work is aimed at enhancing cell adhesion and proliferation on the surface of several starch based polymer blends that are being proposed as tissue engineering scaffolds.

The surface of the polymeric biomaterials was chemically modified using a $\mathrm{KMnO}_{4} / \mathrm{HNO}_{3}$ system. This treatment resulted in more hydrophilic surfaces, which was confirmed by contact angle measurements. The effect of the treatment on the bioactivity of the surface modified biomaterials was also studied. The bioactivity tests, performed in simulated body fluid after biomimetic coating, showed that a dense film of calcium phosphate was formed after 30 days. Finally, human osteoblast-like cells were cultured on unmodified (control) and modified materials in order to observe the effect of the presence of higher numbers of polar groups on the adhesion and proliferation of those cells. Two of the modified polymers presented changes in the adhesion behavior and a significant increase in the proliferation rate kinetics when compared to the unmodified controls.

(C) 2005 Springer Science + Business Media, Inc.

\section{Introduction}

The combination of suitable mechanical and degradation properties constitutes one of the main advantages of starch-based polymers for use on temporary biomedical applications. However, materials must not only be mechanically but also biologically compatible. Adequate surface modification of biomaterials can enhance its biocompatibility without sacrificing its key physical properties.

In fact, many of the surface characteristics may be adjusted by controlling the presence and the density of polar groups because their presence largely influ- ences the surface free energy. Furthermore some types of polar groups can be used as a chemical handle for the improvement of adhesion by chemical bonding or for the covalent coupling of bioactive molecules [1].

There are several methods available for surface functionalization [2]: adsorption, plasma techniques, grafting, and chemical modification. In order to obtain stable surfaces the adsorption or physical deposition of amphiphilic molecules can be used. There is one basic requirement for these molecules-they should be irreversibly adsorbed on the surface, which restricts 
the applicability of this modification method. Gas discharge techniques are also extensively used [3] to functionalize polymer surfaces. The surface modification is obtained by exposing the material to a partially ionized gas-plasma. The main advantage of this method is that it almost exclusively modifies the polymer surface. However, the chemical composition of the surface obtained in this way is usually less defined than would be desirable. Besides plasma, some other methods [4] can be used to create radicals or peroxides on the surface for grafting purposes, namely $\gamma$-radiation, electrons, UV and chemical activation

Starch based biomaterials have been proposed for several biomedical applications, including bone fixation/replacement $[5,6]$, filling of bone defects, partially degradable bone-cements [7-9], drug delivery carriers $[10,11]$, and tissue engineering scaffolds [12-14]. For the latter application, it is of utmost importance to maximize cell adhesion and proliferation, as many biodegradable systems do not have ideal surface characteristics for cell adhesion.

It has been shown that a compromise between several properties of the surface of a biomaterial that determine cellular adhesion and proliferation must be achieved. Changes in the chemistry and topography of the materials lead to differences on the deposition of serum proteins in turn responsible for the biological response $[15,16]$. Improved hydrophilicity resulting from surface modification techniques was found to be responsible for increasing cell adherence and proliferation in different materials and with several cell types [17-19].

The aim of this study was to improve cell adhesion/proliferation on starch-based polymeric biomaterials by surface modification. Starch-based blends were chemically modified using a $\mathrm{KMnO}_{4} / \mathrm{HNO}_{3}$ oxidizing system. The effect of the modification on the adhesion and proliferation of osteoblast-like cells was screened in a preliminary basis. According to the literature, the system $\mathrm{KMnO}_{4} /$ acidic medium is an effective initiator for the graft copolymerisation of some vinyl monomers onto starch [20-23], cellulose [24, 25] and other materials $[26,27]$. Some other promoters of free radical formation such as $\mathrm{H}_{2} \mathrm{O}_{2} /\left(\mathrm{NH}_{4}\right)_{2} \mathrm{~S}_{2} \mathrm{O}_{8}$ [28] or plasma activation $[28,29]$ have been also proposed, all of those resulting in a more polar surface. The application of the system $\mathrm{KMnO}_{4} /$ acidic medium without monomer treatment was not tried before, therefore, the effect and mechanism of the activation of the process is not known.

\section{Materials and methods}

\subsection{Materials}

The materials were: (i) a blend of corn starch (50/50 wt $\%$ ) and ethylene vinyl alcohol (SEVA-C), (ii) a blend of corn starch (50/50 wt\%) and cellulose acetate (SCA), (iii) a blend of corn starch (30/70 wt \%) and polycaprolactone (SPCL). The materials were kindly supplied by Novamont, Italy.

All the materials were processed into disk samples $(\varnothing 1 \mathrm{~cm})$ by injection moulding and their surface modified subsequently. All the tests were performed with ethylene oxide sterilized samples.
Potassium permanganate and nitric acid were reagent grade chemicals and were used as received.

\subsection{Surface modification}

All samples were washed for $24 \mathrm{~h}$ with distilled water and dried at room temperature before treatment. The disks were immersed in an appropriate volume (one milliliter for each sample) of $0.5 \mathrm{M} \mathrm{HNO}_{3}$ and magnetically stirred for $1 \mathrm{~h}$. They were taken out of solution and immersed in potassium permanganate $(0.006 \mathrm{M}$ aqueous solution, $30 \mathrm{~min}$ ), washed with distilled water and dried at room temperature.

\subsection{FTIR analysis}

The FTIR spectra were recorded on a Perkin Elmer System 1600 FTIR with an attenuated total reflectance (ATR) device from SPECAC. Spectra were taken with a resolution of $2 \mathrm{~cm}^{-1}$ and were averaged over 36 scans.

\subsection{Contact angle measurements}

The static contact angle measurements were obtained by the sessile drop method using a contact angle meter OCA15+ with high-performance image processing system from DataPhysics Instruments, Germany. The used liquids $\left(\mathrm{H}_{2} \mathrm{O}\right.$ or $\mathrm{CH}_{2} \mathrm{I}_{2}, 1 \mu \mathrm{l}$, HPLC grade $)$ were added by a motor driven syringe at room temperature. Five sterile samples of each material were used and six measurements were carried out for each sample. The presented data was calculated using the final averaged values. The polarity of the surface as well as the surface tension was calculated by Owens-Wendt equation.

\subsection{X-ray photoelectron spectroscopy}

The XPS analysis was performed using an ESCALAB 200A, VG Scientific (UK) with PISCES software for data acquisition and analysis. For analysis, an achromatic $\mathrm{Al}(\mathrm{K} \alpha) \mathrm{X}$-ray source operating at $15 \mathrm{kV}(300 \mathrm{~W})$ was used. The spectrometer calibrated with reference to Ag 3d5/2 (368.27 eV) was operated in CAE mode with $20 \mathrm{eV}$ pass energy. XPS take-off angle was $90^{\circ}$ (normal to the surface). Data acquisition was performed with a pressure lower than $10^{-6} \mathrm{~Pa}$.

The value of $285 \mathrm{eV}$ of the hydrocarbon $\mathrm{C} 1$ s core level was used as a calibration for the absolute energy scale. Overlapping peaks were resolved into their individual components by use of XPSPEAK 4.1 software.

\subsection{Swelling and degradation tests}

The hydration degree and degradation behavior of the modified materials were studied over a period of 30 days. The samples were immersed in $10 \mathrm{ml}$ of an isotonic saline solution $(0.154 \mathrm{M} \mathrm{NaCl}$ aqueous solution, $\mathrm{pH}=7.4$ ). The swelling was calculated after removing the specimens from solution after 1, 3, 7, 14 and 30 
days:

$$
\% \text { water up take }=\frac{M_{\mathrm{w}}-M_{\mathrm{i}}}{M_{\mathrm{i}}} \times 100
$$

' $M_{i}$ ' is the initial weight of the sample and ' $M_{\mathrm{w}}$ ' is its weight after removing from the solution, washing with distilled water, and soft-blotting with filter paper.

The degradation was calculated by:

$$
\% \text { weight loss }=\frac{M_{\mathrm{i}}-M_{\mathrm{f}}}{M_{\mathrm{i}}} \times 100
$$

' $M_{\mathrm{f}}$ ' is the weight obtained after drying of the samples at $60^{\circ} \mathrm{C}$ to constant weight. Triplicate samples were used for every measurement.

\subsection{Coating of modified samples with a calcium-phosphate layer}

In order to try to coat the modified samples with a calcium-phosphate (Ca-P) layer similar to the inorganic constituent of human bones, each of the modified samples were incubated separately in $10 \mathrm{ml} 0.5 \mathrm{M} \mathrm{CaCl}_{2}$ aqueous solution for 4 days at $37^{\circ} \mathrm{C}$, washed with distilled water and dried. Modified materials were then immersed in a simulated body fluid solution for 1,3 , 7, 14 and 30 days at the same temperature. The SBF was renewed every two days in order to have $\mathrm{Ca}^{2+}$ and $\left(\mathrm{PO}_{4}\right)^{3-}$ ions always available to form the calciumphosphate coating. After this time, the samples were washed, dried and analyzed by Leica Cambridge S360 Scanning Electron Microscopy (SEM).

\subsection{Cell culture}

Cell culture studies using an osteoblastic cell line were performed in order to evaluate the effects of surface modification on cell adhesion and proliferation. A human osteosarcoma cell line SaOs-2, an immortalized cell line with an osteoblastic phenotype, was obtained from European Collection of Cell Cultures (ECCC, UK). The cells were cultured in Dulbecco's modified Eagle's medium (DMEM; Gibco BRL, Life Technologies, USA) supplemented with $10 \%$ of heat-inactivated fetal bovine serum (FBS; Biochrom AG, Germany), $100000 \mathrm{U} / \mathrm{ml}$ penicillin-G, $100 \mu \mathrm{g} / \mathrm{ml}$ streptomycin and $25 \mu \mathrm{g} / \mathrm{ml}$ amphotericin B (Sigma Chemical Co, USA) and $20 \mathrm{mM}$ Hepes (Sigma Chemical Co, USA) in a humidified atmosphere with $5 \% \mathrm{CO}_{2}$, at $37^{\circ} \mathrm{C}$.

\subsection{Cell morphology}

Cells were cultured on the various materials at different time periods in order to identify morphological changes resulting from the surface modification treatment.

In this assay cells were trypsinised $(0.25 \%$ trypsin/EDTA solution, Sigma Chemical Co, USA) from a culture flask and $1.5 \mathrm{ml}$ of SaOs-2 suspension $\left(3.3 \times 10^{-4}\right.$ cells $/ \mathrm{ml}$ in fresh culture medium) were added to the materials. The 24 -well plates were incubated for 1,3 and 7 days. Three samples per material per time point were studied and tissue culture polystyrene wells were used as control. Culture medium was changed every two days and after each predetermined time of culture the cells were washed with a $0.1 \mathrm{M}$ phosphate buffered saline solution (PBS, Sigma Chemical Co, USA), fixed with $2.5 \%$ gluteraldehyde (BDH, UK) solution in PBS for 30 min at $4{ }^{\circ} \mathrm{C}$, washed and kept in PBS at $4{ }^{\circ} \mathrm{C}$ prior to histological staining.

In order to infer about the number of cells on the surface of each material cells were stained with a $0.4 \%$ methylene blue solution in water for 1 min and examined under a stereomicroscope.

\section{Results and discussion}

\subsection{Surface modification}

Two different mechanisms for the reaction between polymers and $\mathrm{KMnO}_{4}$ have been proposed in the literature (see schemes below). They are dependent on many factors: the reactive groups on the polymer, the concentration of $\mathrm{KMnO}_{4}$, the activator, the $\mathrm{pH}$, etc. Polymers, functionalized with permanganate groups, were produced by reaction of $\mathrm{KMnO}_{4}$ with crosslinked polyvinylamine [27], methyl cellulose [25] or pectin polysaccharide [30] using different activators and $\mathrm{pH}$ range. The reaction products can be converted into diketones as final products $[25,30]$ :

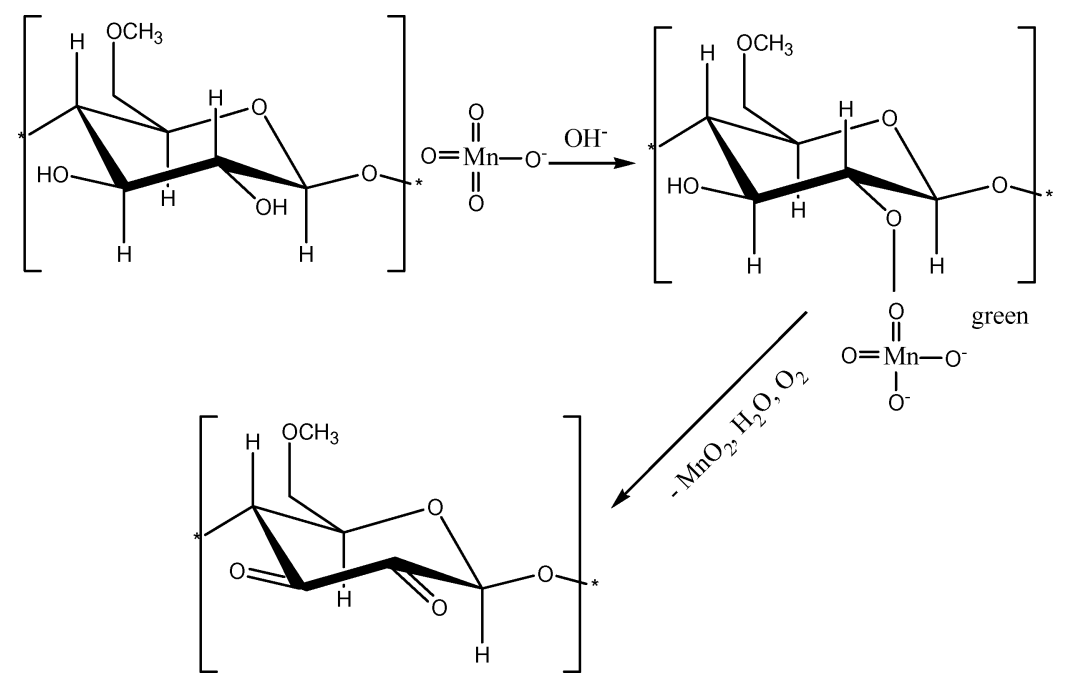


The authors discarded the possibility for the radical reaction mechanism and proved that [25].

The second mechanism is via radicals and it has been described for graft copolymerization onto cotton cellulose [24] as well as onto starch using different monomers and activators [20-22, 31, 32] but always at acidic $\mathrm{pH}$ range.

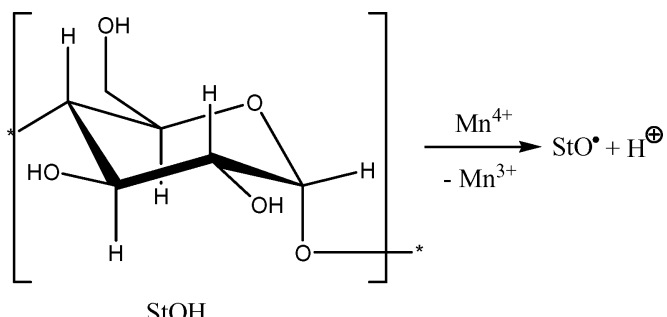

$$
\mathrm{StOH} \underset{-\mathrm{Mn}^{2+}}{\stackrel{\mathrm{Mn}^{3+}}{\longrightarrow}} \mathrm{StO}^{\bullet}+\mathrm{H}^{\oplus}
$$

$\mathrm{StO}^{\bullet}+\mathrm{M} \longrightarrow \mathrm{StOM}$; where $\mathrm{M}$ is a grafted monomer
The $\mathrm{pH}$ range at which we carried out the reaction, as well as all performed tests with the modified materials, rejected one of the proposed mechanisms via $\mathrm{MnO}_{4}^{-} \mathrm{im}-$ mobilization. Neither colour change in the green scale was observed during the reaction nor was a $\mathrm{MnO}_{4}^{-}$peak detected by XPS. Furthermore, the treatment of the materials with periodic acid $\left(\mathrm{HIO}_{4} \cdot 2 \mathrm{H}_{2} \mathrm{O}\right)$ [33], which resulted in dialdehyde product, showed a significant toxic effect. Considering the well known toxicity of the aldehyde groups this result is not surprising.

The starch macroradicals produced by $\mathrm{KMnO}_{4} /$ $\mathrm{HNO}_{3}$ treatment react with the oxygen from the air enriching the surface in oxygen by the formation of peroxide and carboxylic groups. The introduced polar groups change the surface behaviour and this fact is of great importance especially for biomedical materials, which are permanently in contact with hydrated media. The aim of the following tests was to understand and to predict the interaction of the examined materials in such a media.

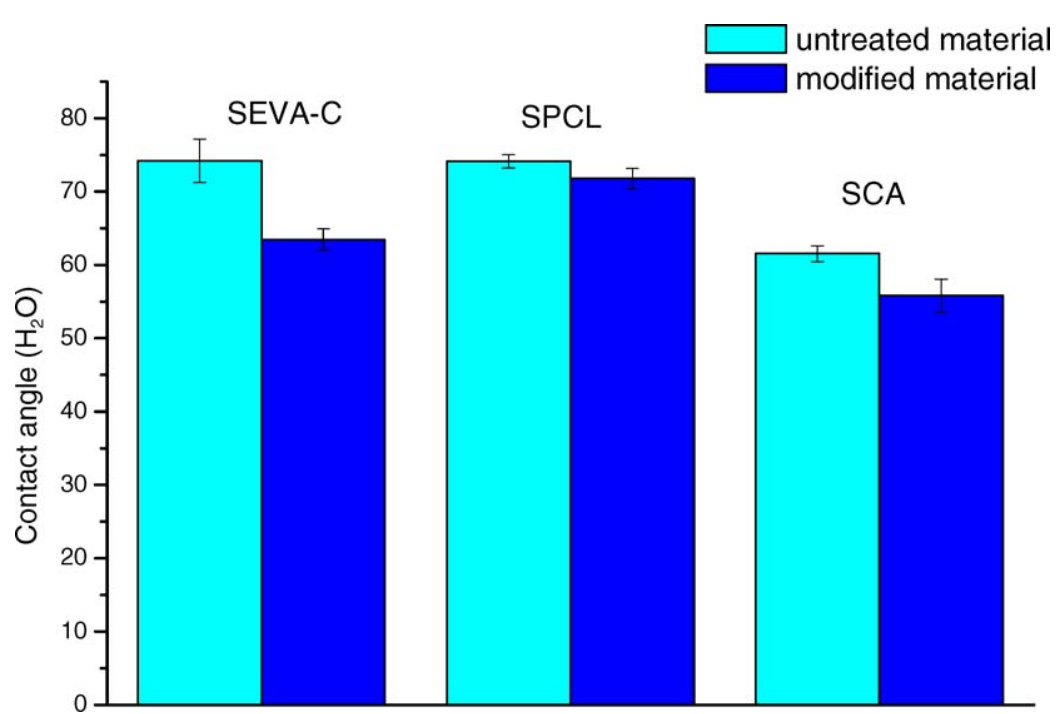

Figure 1 Water contact angles for untreated and modified starch-based polymers surfaces. The error bars represent standard deviation $(n=5)$.

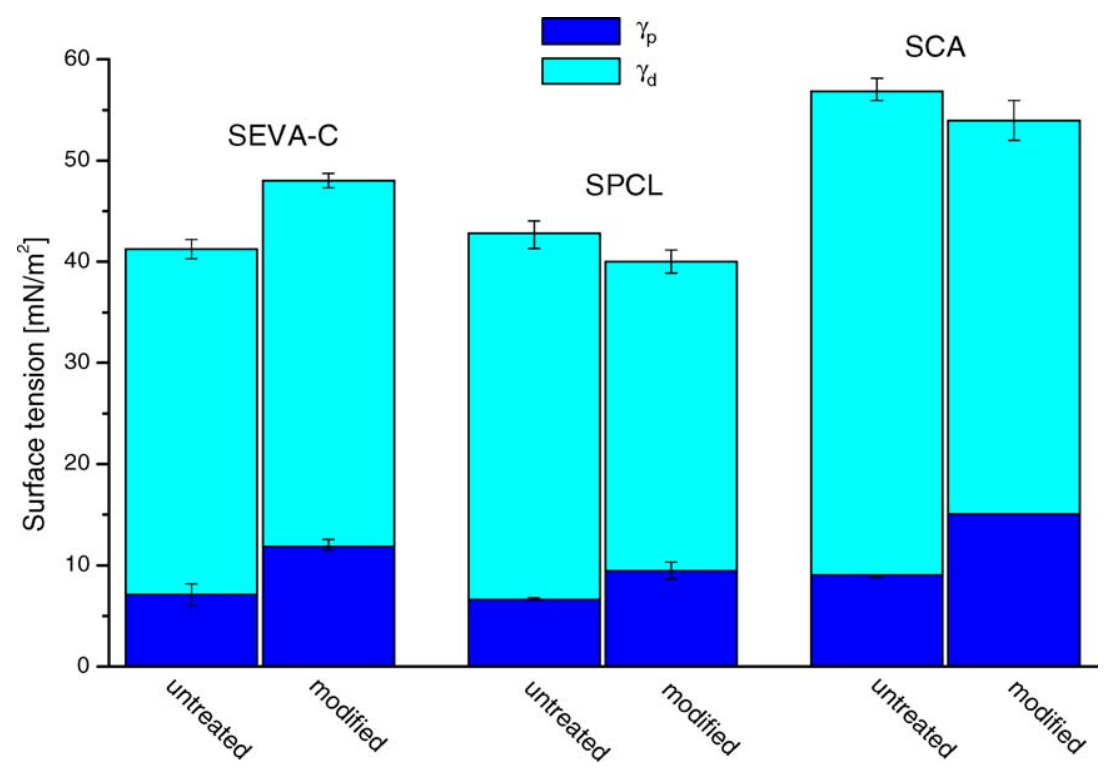

Figure 2 Surface tensions, polar $\left(\gamma_{\mathrm{p}}\right)$ and dispersion $\left(\gamma_{\mathrm{d}}\right)$ components for untreated and modified starch-based polymers surfaces calculated by Owens-Wendt equation. 


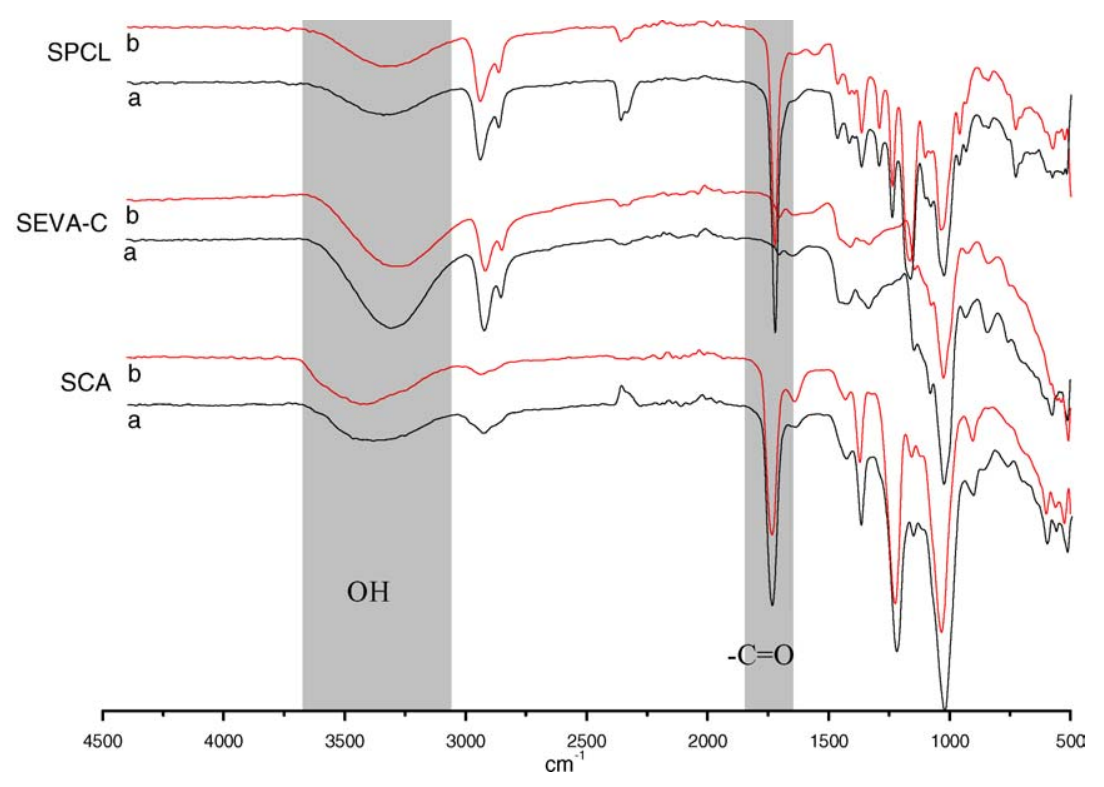

Figure 3 FTIR spectra of original (a) and chemically modified (b) SCA, SEVA-C and SPCL, surfaces.

A

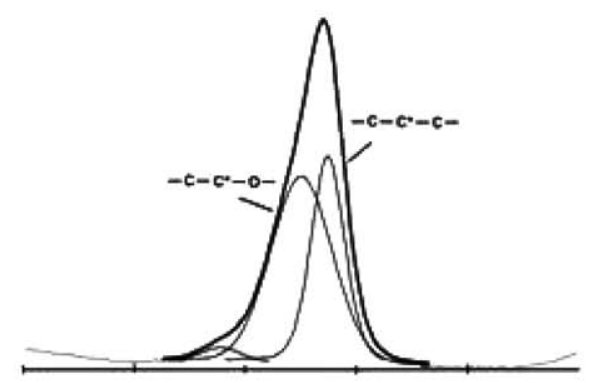

B
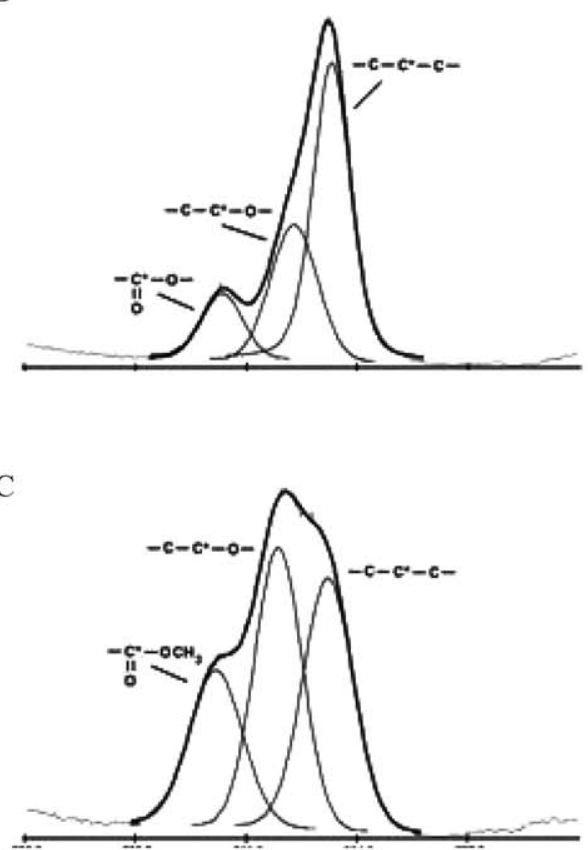

D

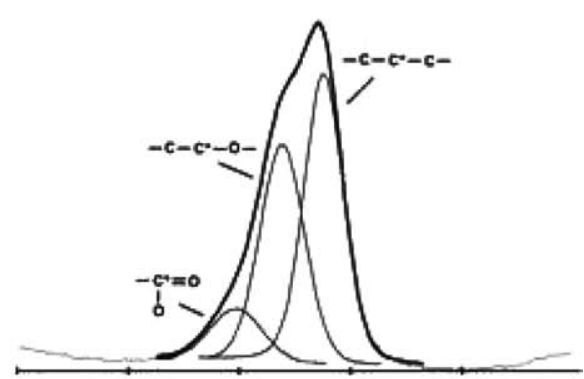

E

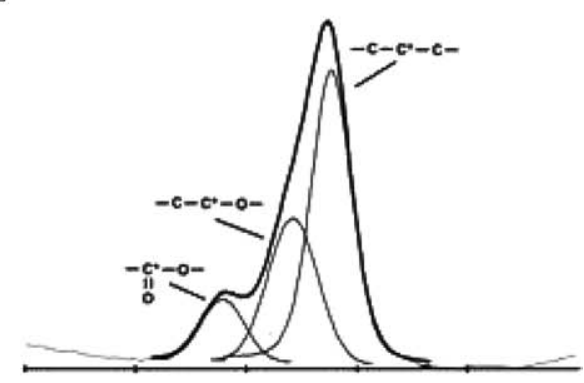

F

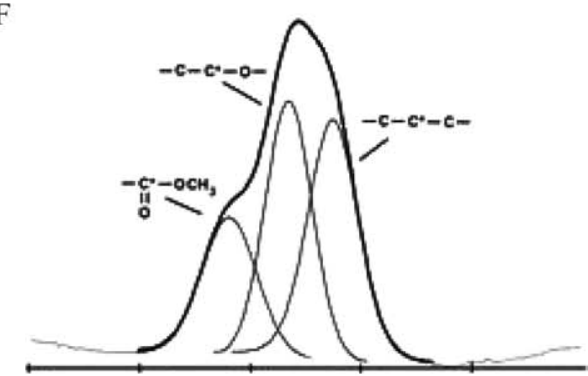

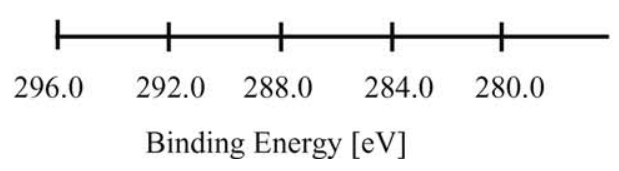

Figure 4 XPS C1s spectra of orginal SEVA-C (A), SPCL (B), SCA (C) and modified (D, E, F) materials. 


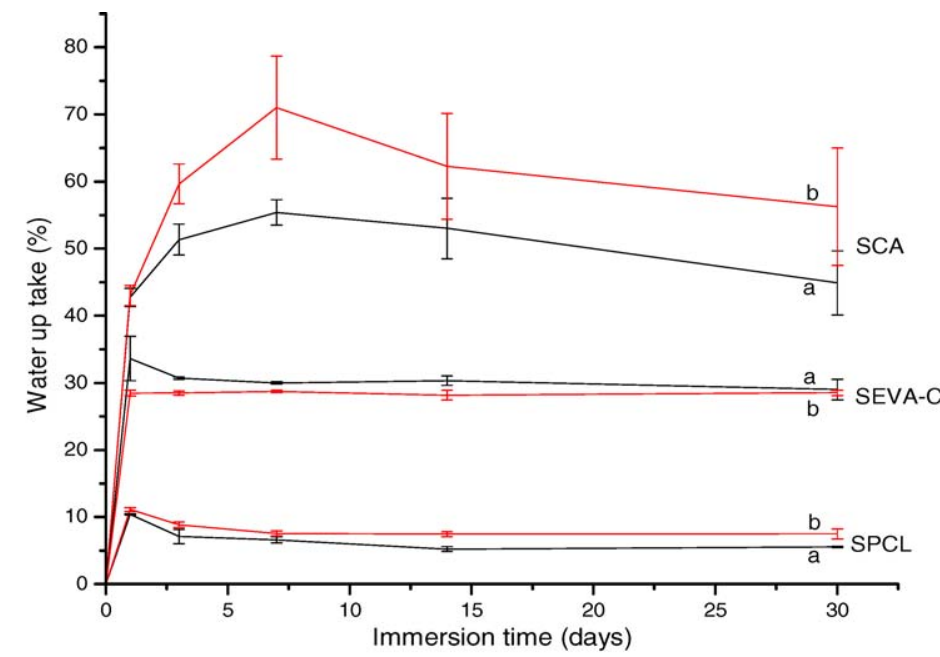

(a)

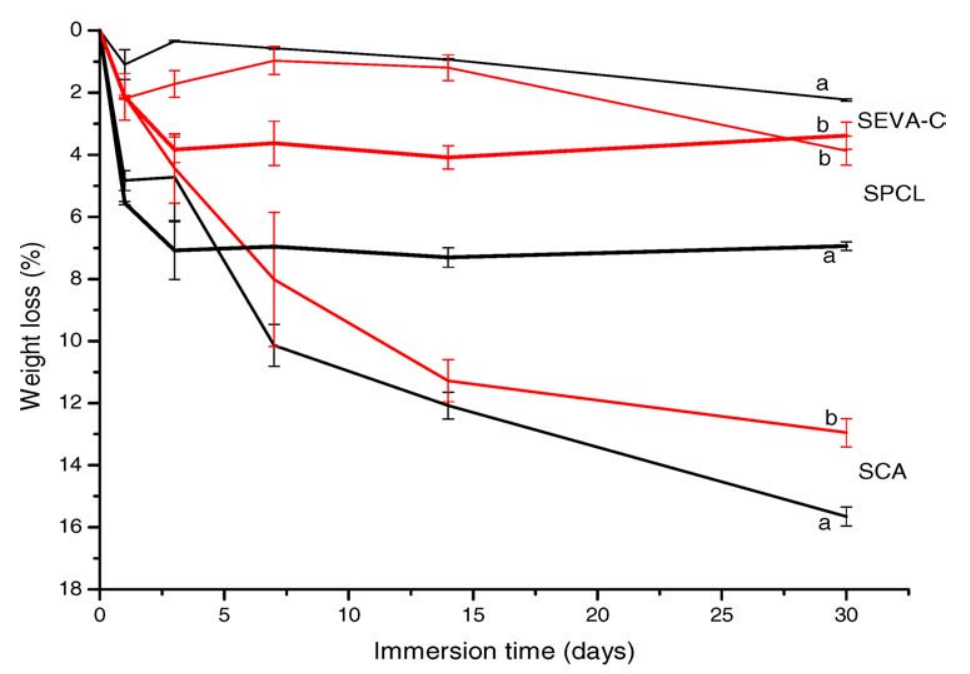

(b)

Figure 5 Swelling and degradation behavior of the materials before (a) and after (b) modification.

\subsection{Contact angle measurements}

Contact angle measurements were carried out in order to study the changes of the wettability of the surfaces after potassium permanganate treatment. As expected, and according to the already proposed mechanism, a decrease of average water contact angle was observed for all treated materials (Fig. 1).

The increase in the hydrophilicity of the surfaces after this treatment may be justified by the higher amounts of polar groups as compared with the untreated samples. These groups are easily solvated by water molecules, the testing liquid used during these measurements. The presence of more polar groups was also confirmed by surface tension calculations (Fig. 2). The polar compo-

TABLE I Experimental binding energies and composition of original and modified materials determined by XPS

\begin{tabular}{lllll}
\hline Material & Binding energies (eV) & $\% \mathrm{C}$ & $\% \mathrm{O}$ & $\begin{array}{l}\mathrm{C} / \mathrm{O} \\
\text { ratio }\end{array}$ \\
\hline SEVA-C & $285.03,285.98$ & 56.75 & 43.25 & 1.31 \\
SEVA-C, modified & $284.97,286.46,288.1$ & 45.21 & 54.79 & 0.83 \\
SPCL & $284.93,286.29,288.87$ & 51.06 & 48.94 & 1.04 \\
SPCL, modified & $284.93,286.31,288.84$ & 48.40 & 51.60 & 0.94 \\
SCA & $285.04,286.83,289.07$ & 38.48 & 61.52 & 0.63 \\
SCA, modified & $285.02,286.62,288.76$ & 37.91 & 62.09 & 0.61 \\
\hline
\end{tabular}

nent increases for all modified materials compared to the untreated surfaces.

\subsection{Fourier transform infrared spectroscopy}

Fig. 3 shows the FTIR spectra of treated starch based materials. According to the reaction mechanism and the expected products, the bands in the spectra corresponded to oxygen containing groups, i.e., the carbonyl and the hydroxyl bands, have to change after treatment.

The starch is rich in hydroxyl groups and as a consequence this part (at around $3000-3500 \mathrm{~cm}^{-1}$ ) of the spectrum is not very informative. We can also observe the bands characteristic for the carbonyl groups (at about $1700 \mathrm{~cm}^{-1}$ ) in the spectra for untreated SPCL and SCA. Their appearance is due to the second component in the blends. The changes in the spectra for treated materials are not so significant. This could be expected consider both the sampling depth, which can be analyzed by FTIR-ATR - up to a micrometer or more, and the striving for topmost layer modification. A decrease in the intensity of bands in the hydroxyl area, can be observed in the spectra of SEVA-C and SPCL treated with $\mathrm{KMnO}_{4}$. It is probably due to the oxidation and conversion of hydroxyl groups into carbonyl containing 
groups. Generally, in all treated materials spectra, the signals for the carbonyl groups (at about $1700 \mathrm{~cm}^{-1}$ ) are more intensive than observed for the untreated samples, i.e., the number of those groups is increasing.

\subsection{X-ray photoelectron microscopy}

The results presented in Table I clearly show that after treatment the oxygen contents increase for all studied blends.

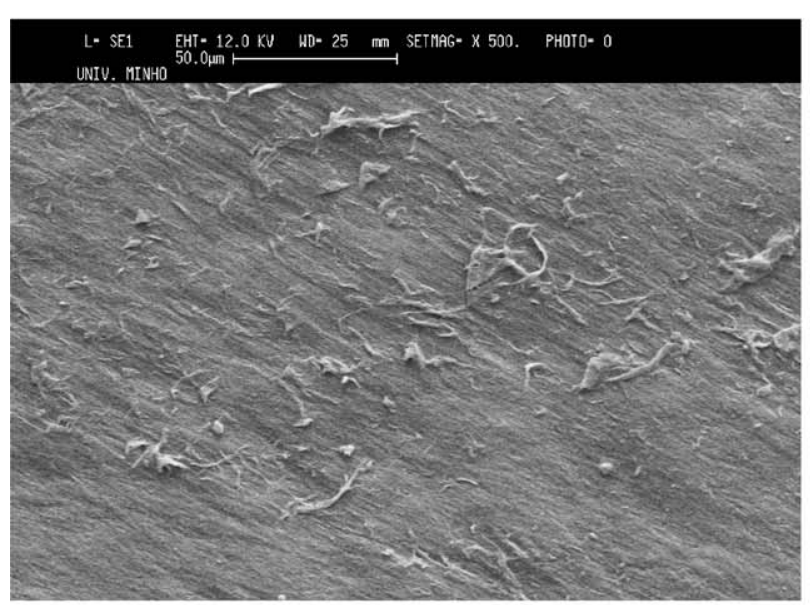

(a)

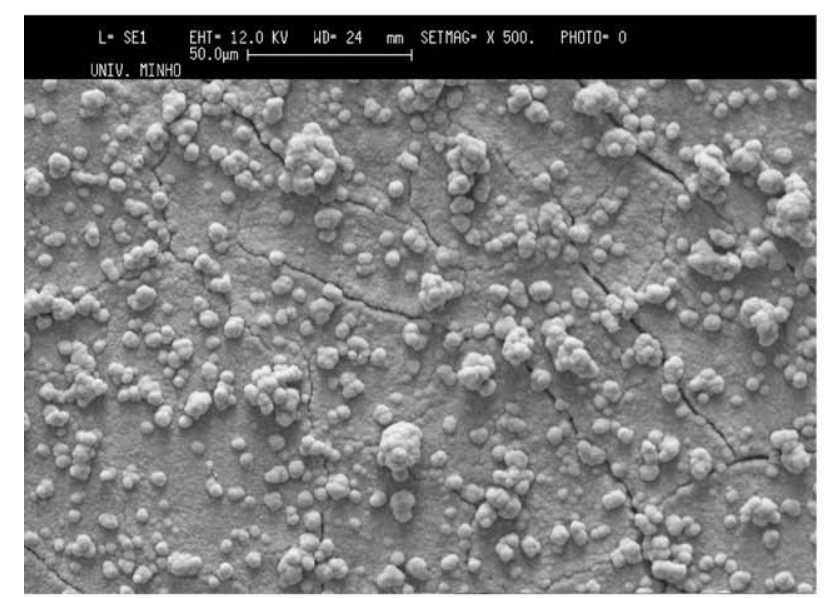

(c)

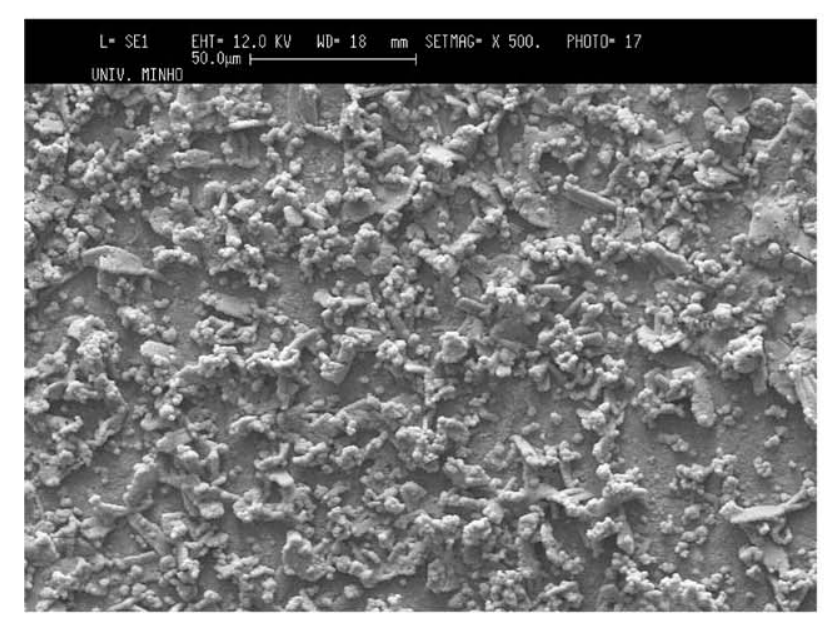

(e)
It should be noted that the amount of oxygen introduced by the potassium permanganate modification is dependent on the oxygen present in the untreated blend. The increase is very significant for SEVA-C, the blend which has less oxygen before treatment, and not significant for SCA.

The $\mathrm{C} 1 \mathrm{~s}$ core level spectra of all original blends consist of a doublet due to the presence of the starch-at about $285 \mathrm{eV}$ the main backbone carbon peak and about

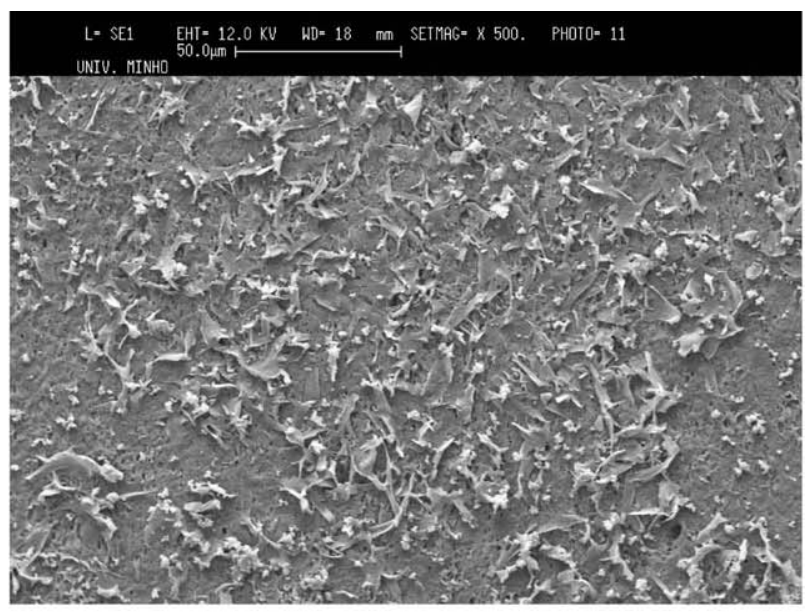

(b)

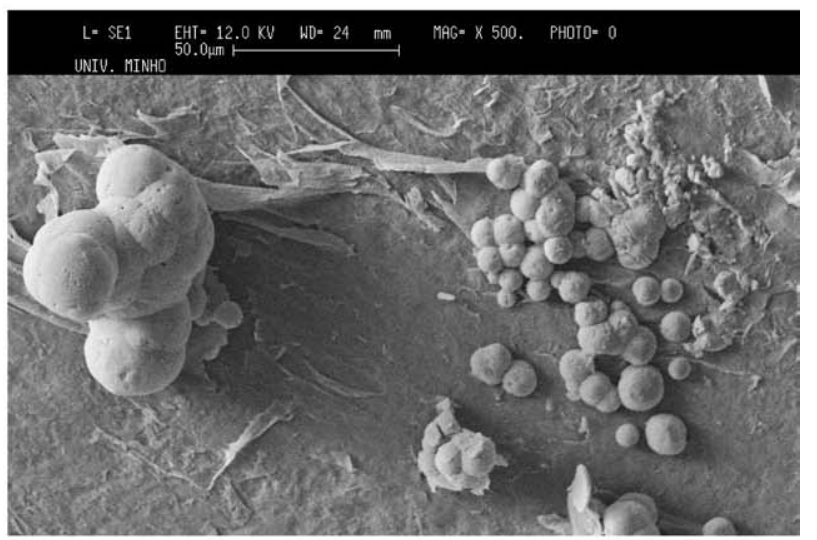

(d)

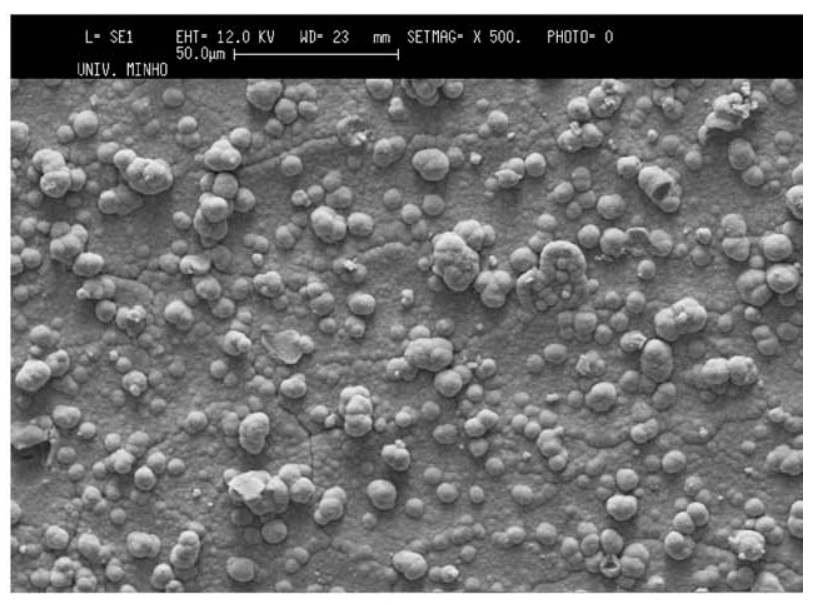

(f)

Figure 6 SEM micrographs of treated SCA, SPCL, and SEVA-C respectively after 3 (a, b, and c), 14 (d, e, and f) and 30 (g, h, and i) days immersing in SBF. (Continued on next page.) 


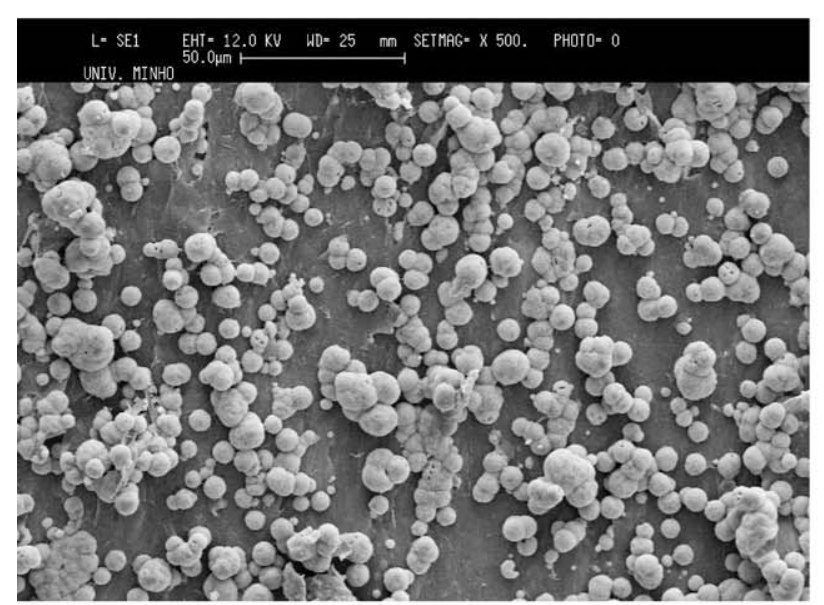

(g)

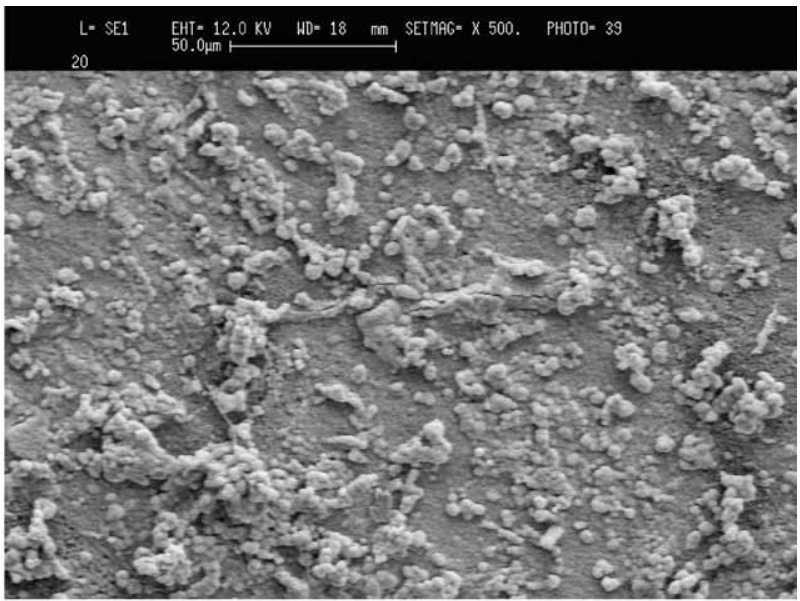

(h)

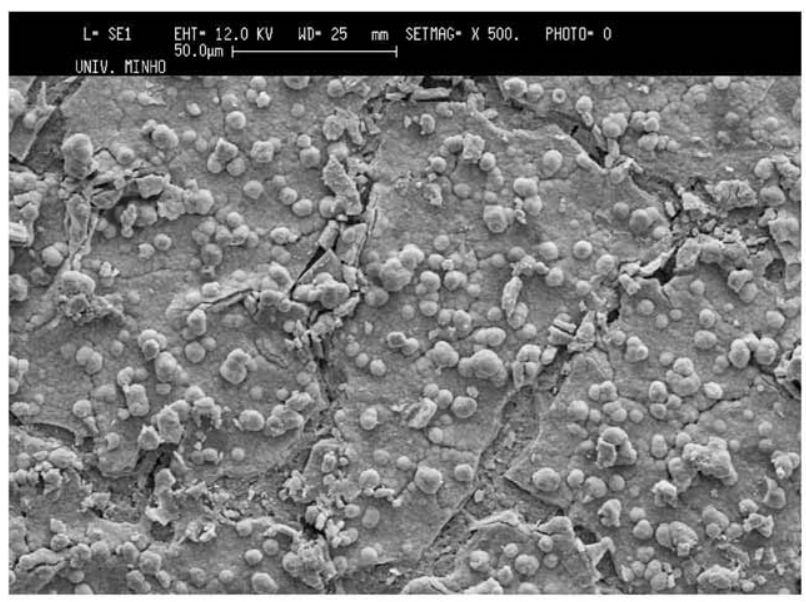

(i)

Figure 6 (Continued)

$286 \mathrm{eV}$ for the hydroxyl bonded carbons (Fig. 4(a), (b) and (c)).

The third peak in the spectra of SPCL (Fig. 4(b)) and SCA (Fig. 4(c)) at about $289 \mathrm{eV}$ corresponds to the carbonyl carbons which are presented in the second component of the blends (polycaprolactone and cellulose acetate, respectively). After treatment a new signal (288.1 eV, Fig. 4(d)) appears in the C1s spectra of modified SEVA-C. The chemical shift for the signal is in an agreement with this determined for $-\mathrm{OC}=\mathrm{O}$ bonded carbons. A line broadening was observed in $\mathrm{C} 1 \mathrm{~s}$ core level spectra of treated SPCL (Fig. 4(e)). After fitting, it was found that an increase of $-\mathrm{C}-\mathrm{O}$ component intensity is the reason for the broadening. These results show that more polar groups, namely $\mathrm{COOH}$ and $\mathrm{OH}$, have been introduced on the surface. The results are in agreement with both the reaction mechanism and the results from contact angle measurements.

\subsection{Swelling and degradation tests}

Swelling and degradation tests were also performed in order to understand the behavior of the materials after the modifications to the surfaces were introduced, in the presence of simulated body fluids. The observed differences in the behavior of the different materials are due to the second component present in the blends. As can be expected in most cases the water uptake ability was increased after treatment with potassium permanganate-this is especially clear for SCA (Fig. 5).

The differences in the behavior of SEVA-C and SPCL after treatment are insignificant. The presence of more polar groups on the substrate leads to a more hydrophilic surface. This is of great importance in the beginning of the uptake process when materials first contact with solution. Then the kinetic of solution penetration is the determining factor for the amount of water taken up. The second component in SCA, cellulose acetate, is quite bulky and makes diffusion easier. Furthermore, it is well known that the cellulose acetate itself swells. The observed lower water uptake ability for SEVA-C and SPCL is due to the relatively more compact structure determined by the poly(ethylene-vinyl alcohol) and poly(caprolactone) respectively. The role of polar hydroxyl groups in SEVA-C is evident if we compare its behavior with SPCL in which the second component (polycaprolactone) is hydrophobic and takes up less water.

As can be seen from Fig. 5 the major weight loss for all materials occurs within the first few days. This is due to the plasticizers that leach out from the materials [34]. The comparisons between the behavior of treated and untreated samples do not show big differences, which confirm that the performed surface modification did not 


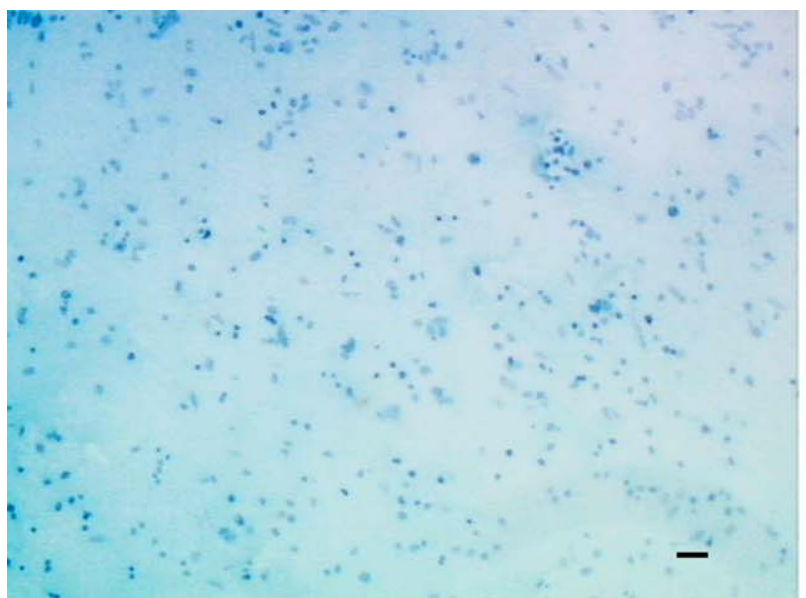

(a)

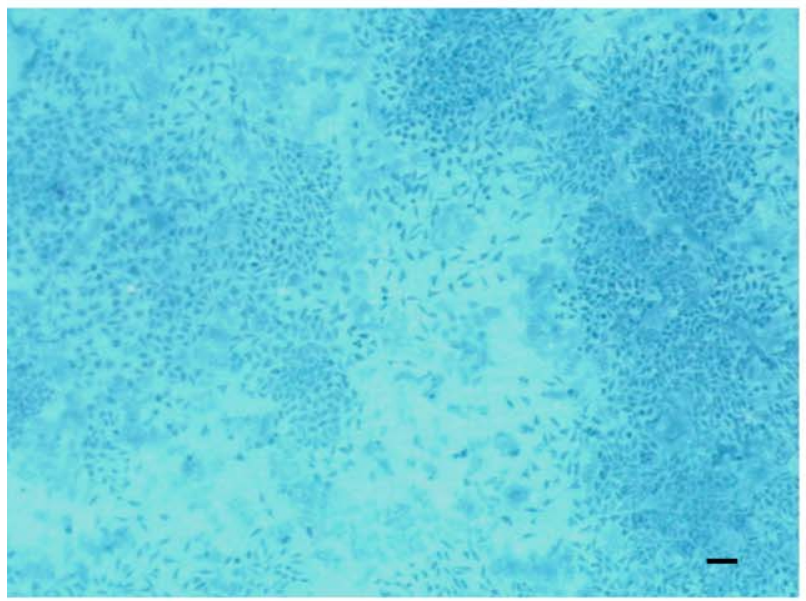

(c)

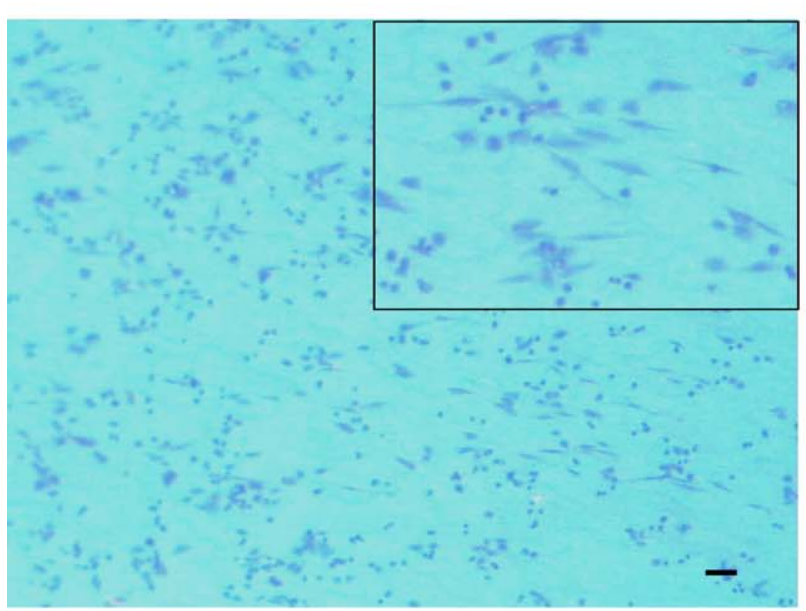

(e)

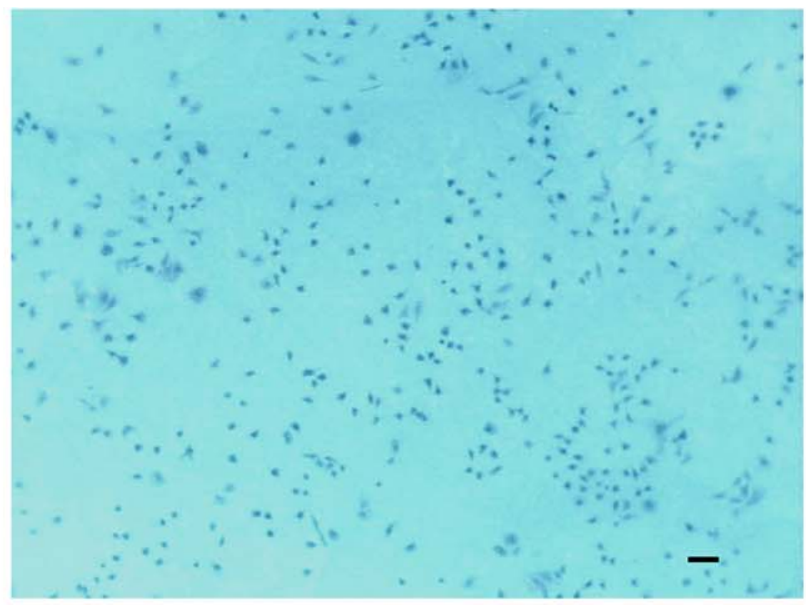

(b)

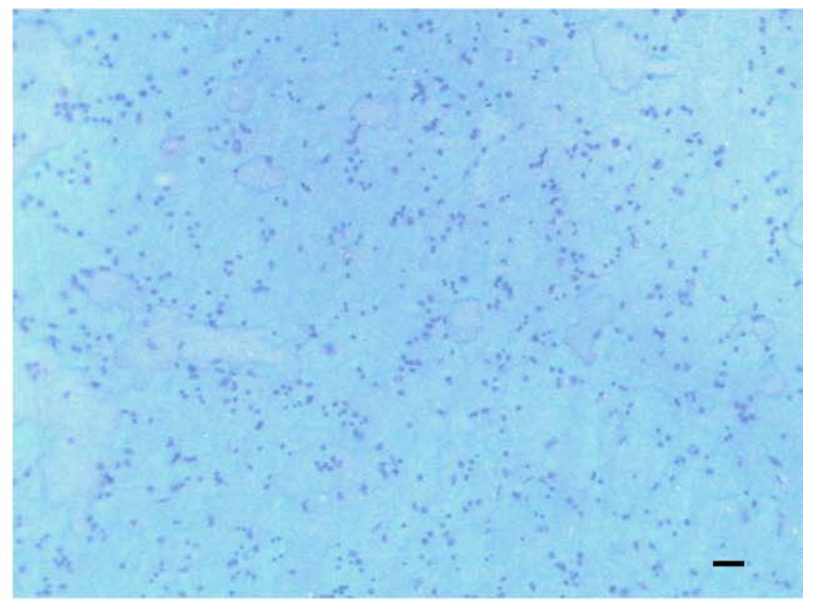

(d)

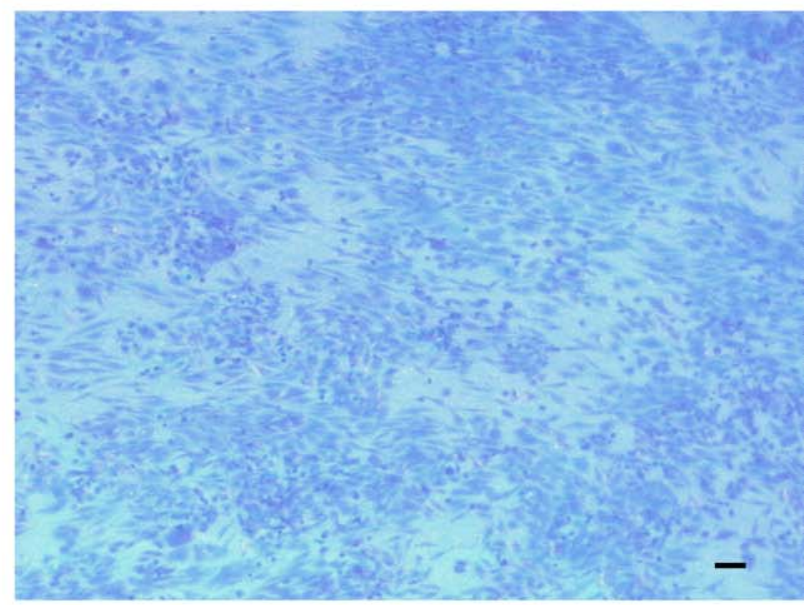

(f)

Figure 7 Optical micrographs of osteoblast-like cells stained with methylene blue cultured on untreated (a, b and c) and treated SEVA-C (d, e and f) for 1,3 and 7 days. Bar represents $100 \mu \mathrm{m}$.

compromise the degradability nature of the investigated materials.

\subsection{Coating of modified samples with a calcium-phosphate layer}

The study of the influence of the potassium permanganate treatment over the induction and growing of a biomimetic calcium-phosphate coating was the aim of these tests. The increase of polar groups on the surface is known to be an effective way to create more favorable sites for apatite formation since they can form a fairly strong bond with calcium ions [35]. In contrast, the inhibitory effect of $\mathrm{Mn}^{2+}$ on apatite formation is also known [36]. Fig. 6 shows the surface of treated samples after different immersion time periods. After 3 days of SBF immersion, a few apatite nuclei were observed on SCA (Fig. 6(a)) and more on SPCL (Fig. 6(b)) surface. 


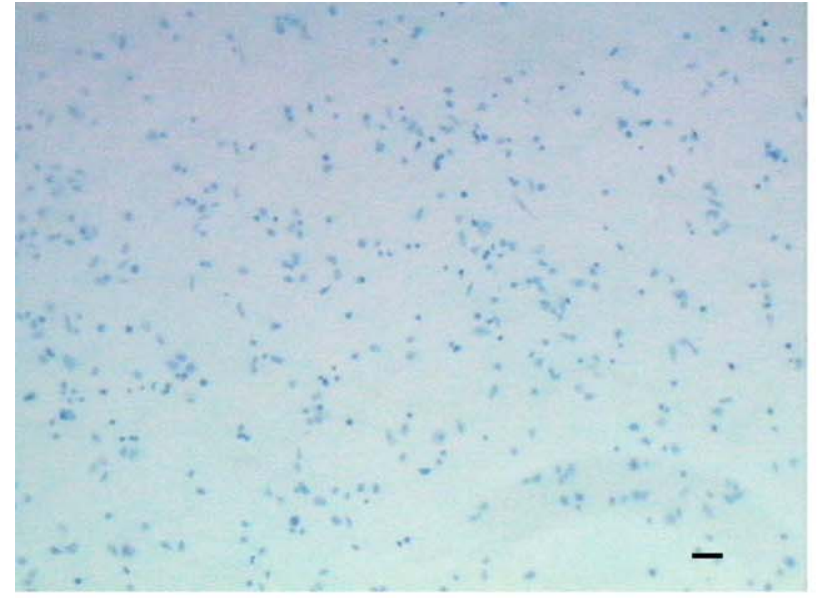

(a)

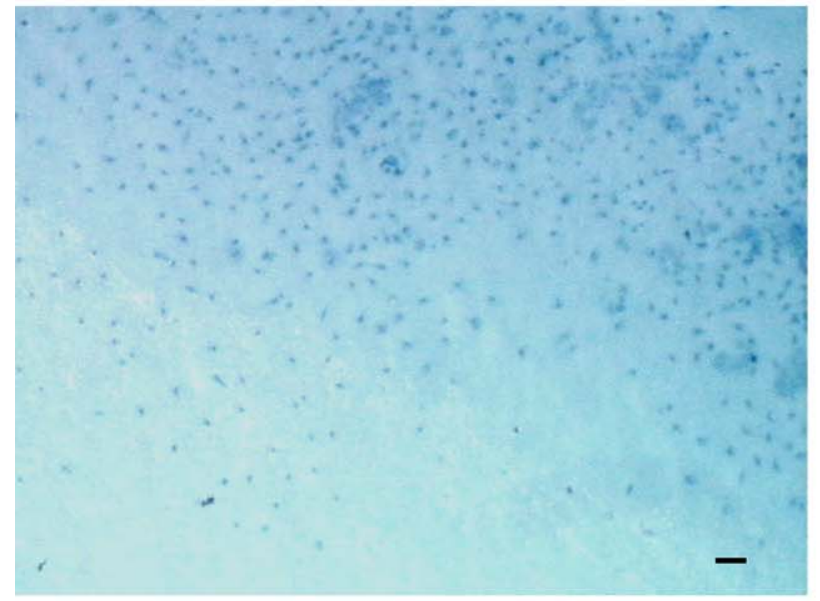

(c)

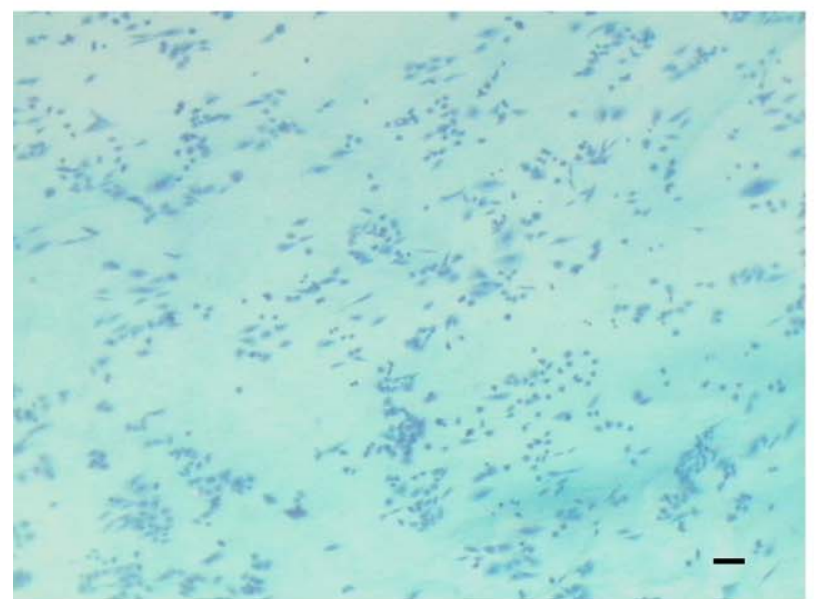

(e)

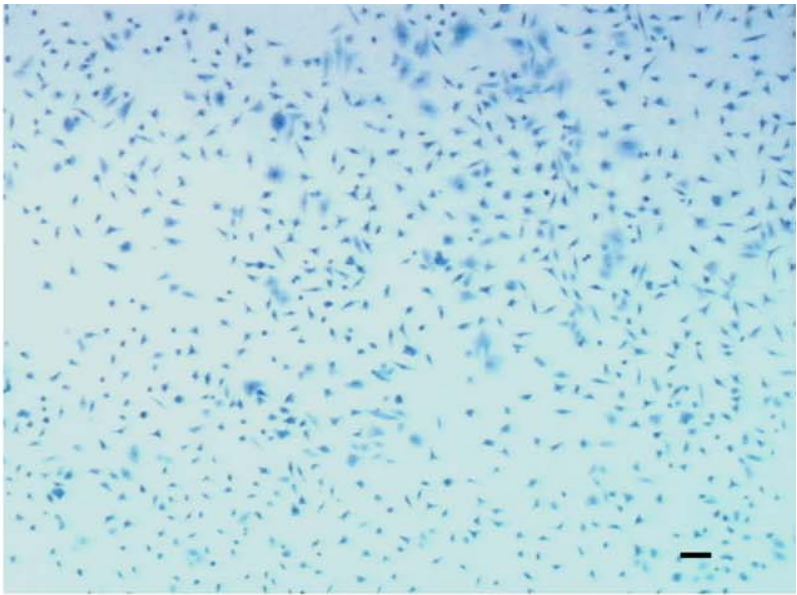

(b)

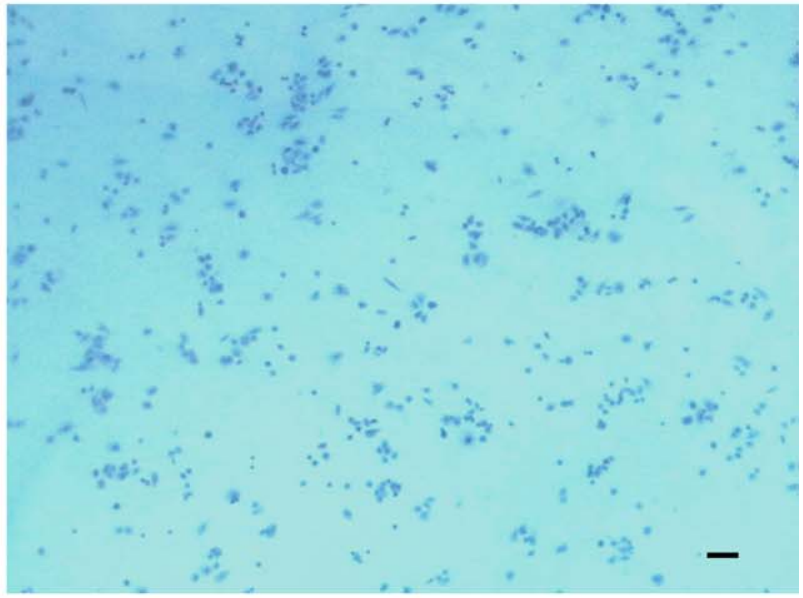

(d)

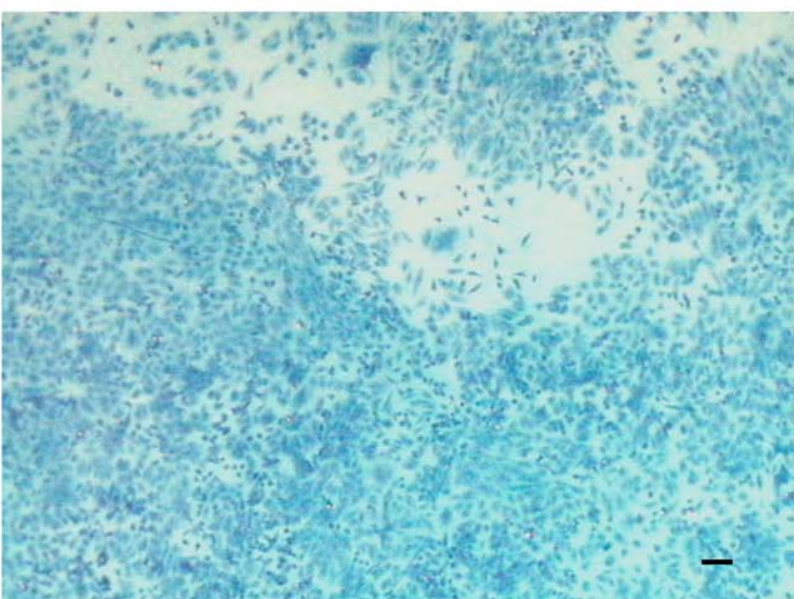

(f)

Figure 8 Optical micrographs of osteoblast-like cells stained with methylene blue cultured on untreated (a, b and c) and treated SPCL (d, e and f) for 1,3 and 7 days. Bar represents $100 \mu \mathrm{m}$

This was also confirmed by Energy Dispersive X-ray Spectroscopy (EDS). The amount of the apatite nucleus formed increases with time, and at the end of the study period, a dense film of calcium phosphate could be observed on the materials' surfaces (Fig. $6(\mathrm{~g})$ and (h)). As can be seen from Fig. 6(c), an apatite layer was formed on modified SEVA-C surface only after 3 days, while untreated SEVA-C did not show any apatite formation for fourteen days [37]

\subsection{Cell morphology}

Anchorage dependent cells need to adhere in order to proliferate. Therefore, the way cells adhere and proliferate on the surface of a potential biomaterial is important for function and success of the implant. As the materials in this study are proposed for orthopedic applications, the biological effect of the surface modifications was assessed in cells with osteoblastic phenotype, the predominating cell type facing the devices in vivo. 
Figs. 7 and 8 show the morphology of osteoblastlike cells on the surface of the different starch-based polymers before and after surface modification. The increasing culture times allowed for a qualitative analysis of cellular proliferation.

Osteoblasts in contact with untreated SEVA-C (Fig. 7(a), (b) and (c)) demonstrated adequate adherence to the surface. After 1 day in culture, it was possible to observe rounded cells starting to spread onto the surface. They became well spread on the surface after 3 days of culture. Almost all the surface was covered by a monolayer of cells after 1 week in culture, which is an indication of good proliferation. Although osteoblast adhesion and proliferation on the original blend of starch with ethylene vinyl alcohol are good, the chemical modification of the surface seemed to affect positively the osteoblasts' behavior (Fig. 7(d), (e) and (f)). The higher hydrophilicity induced by the modification might be the reason for the observed variations. It was clear by microscopical observation that cells adhered better to the modified surfaces. In particular, after 7 days of culture, the uncovered material's surface is almost inexistent (Fig. 7(f)). Also the morphology and pattern of adhesion seemed to be affected by the surface treatment. After 3 days it was possible to observe some cells spreading and extending their filopodia in an oriented way (Fig. 7(e)). This cell behavior was kept for 7 days of culture, when the entire layer of cells has shown a certain degree of orientation.

In contrast to SEVA-C, the original surface of SPCL polymer (Fig. 8(a), (b) and (c)) was not so favorable for cell proliferation probably due to the presence of carbonyl groups on the surface. It was observed that after shorter times of culture (1 and 3 days), cells on the surface of SPCL presented the typical polygonal osteoblastic morphology. However, after 7 days of culture they did not seem to be as well adapted to the surface as cells adhered to SEVA-C surface. Again, the presence of carbonyl groups and consequently the surface chemistry of SPCL do not provide adequate osteoblast proliferation due to the lack of cellular anchorage points.

Therefore, the modification of the surface of the blend starch/polycaprolactone using the developed technique represent the major achievement of the present work. Indeed, as it can be observed on Fig. 8(c) and (f), the proliferation of cells attached to the SPCL surface was deeply increased with the surface treatment. It was possible to find cells with extended filapodia only after 1 day of culture and contrarily to the results obtained in the original surface, a monolayer of cells covering the most part of the surface could be observed after one week.

The preferential adhesion pattern observed for modified SEVA-C surfaces was more obvious for SPCL at short periods of culture. After 7 days, almost no orientation of the monolayer was observed for this material when compared to that seen with SEVA-C.

The incorporation of polar groups was proved to improve cellular attachment and proliferation in the case of two of the starch-based polymers in the present study (SEVA-C and SPCL). For SCA we could not, so far, obtain good results and due to this fact we do not report results for cell adhesion and proliferation experiments. The degradation of this material typically leads to some $\mathrm{pH}$ drop. It is known that also some low molecular weight chains formed during the processing (due to some unavoidable thermal degradation of this rather sensitive polymers) leach out to the culture medium inducing cell toxicity.

\section{Conclusions}

The reported surface modification by the system $\mathrm{KMnO}_{4} /$ nitric acid is a very easily applicable method for introducing polar groups on starch based biomaterials. It is an efficient way of enhancing cell adhesion and proliferation on the surface of both SEVA-C and SPCL polymers. The present results might be very useful for tailoring cell adhesion and proliferation on starch based biomaterials and particularly on starch based tissue engineering scaffolds. This is particularly relevant, as it is known that cell adhesion and proliferation are major factors to consider when applying biodegradable polymers as scaffolds for tissue engineering. Furthermore the modified polymers can be easily coated with a biomimetic calcium-phosphate layer.

\section{Acknowledgment}

I. Pashkuleva acknowledges FCT (Portugal) for providing the postdoctoral grant (BPD/8491/2002).

\section{References}

1. S. W U, "Polymer Interface and Adhesion" (Marcel Dekker Inc., New York, 1992).

2. W. J. WARD and T. J. McCARTHY, in "Encycl. Polym. Sci. Eng.”, edited by J. I. Kroschwitz (Wiley, New York, 1990) Vol. (Suppl.), p. 678.

3. N. IGANA KI, "Plasma Surface Modification and Plasma Polymerization" (Technomic Publishing Co., Inc., Basel, 1996).

4. J. G. A. TERLINGEN, A. S. HOFFMAN and J. FEIJEN, J. Appl. Polym. Sci. 50 (1993) 1529.

5. R. A. SOUSA, G. KALAY, R. L. REIS, A. M. CUNHA and M. J. BEVIS, ibid. 77 (2000) 1303.

6. R. L. REIS, A. M. CUNHA and M. J. BEVIS, Med. Plast. Biomater. 4 (1997) 46.

7. C. S. PEREIRA, A. M. CUNHA, R. L. REIS, B. VAZQUEZ and J. SAN ROMAN, J. Mater. Sci. Mater. Med. 9 (1998) 825.

8. I. ESPIGARES, C. ELVIRA, J. F. MANO, B. VAZQUEZ, J. SAN ROMAN and R. L. REIS, Biomaterials 23(8) (2002) 1883.

9. L. F. BOESEL, J. F. MANO and R. L. REIS, J. Mater. Sci. Mater. Med. (2003), in press.

10. C. ELVIRA, J. F. MANO, J. SAN ROMAN and R. L. REIS, Biomaterials 23 (2002) 1955.

11. P. B. MALAFAYA, C. ElVirA, A. GALlARDO, J. SAN ROMAN and R. L. REIS, J. Biomater. Sci. Polym. Ed. 12 (2001) 1227.

12. M. E. GOMES, A. S. RIBEIRO, P. B. MALAFAYA, R. L. REIS and A. M. CUNHA, Biomaterials 22 (2001) 883.

13. M. E. GOMES, R. L. REIS, A. M. CUNHA, C. A. BLITTERSWIJK and J. D. DE BRUIJN, ibid. 22 (2001) 1911.

14. M. E. GOMES, J. S. GODINHO, D. TCHALAMOV, A. M. CUNHA and R. L. REIS, Mater. Sci. Eng. C20(1/2) (2002) 19.

15. B. D. BOYAN, T. W. HUMMER, D. D. DEAN and Z. SCHW A R TZ, Biomaterials 17 (1996) 137. 
16. A. S. CURTIS and C. D. WILKINSON, J. Biomater. Sci. Polym. Ed. 9 (1998) 1313

17. X. YANG, K. ZHAO and G. CHEN, Biomaterials $23(2002)$ 1391.

18. K. CAI, K. YAO, Y. CUI, Z. YANG, X. LI, H. XIE, T. QING and L. GAO, ibid. 23 (2002) 1603.

19. J. H. LEE, H. W. JUNG, I. K. KANG and H. B. LEE, ibid. 15(9) (1994)705.

20. S. A. A B DEL-H AFIZ, Polym. Degr. Stabil. 55 (1997) 9.

21. KH. M. MOSTAFA, ibid. 55 (1997) 125.

22. J. GAO, J. YU, W. WANG, L. CHANG and R. TIAN, $J$. Appl. Polymer. Sci. 68 (1998) 1965.

23. KH. M. MOSTAFA and A. A. El-SAnABARY, Polym Degr. Stabil. 55 (1997) 181.

24. I. C. ER OMOSELE, J. Appl. Polym. Sci. 51 (1994) 1817.

25. R. M. EL-KHATIB, Carbohydr. Polym 47 (2002) 377.

26. A. DAS and C. N. SAIKIA, Biores. Technol. 74 (2000) 213

27. P, V. PRABHAKARAN, S. VENKATACHALAM and K. N. NINAN, J. Eur. Polym. 35 (1999) 1743.

28. C. Elvira, Y. FENG, M. C. AZEVEDO, L. REBOUTA, A. M. CUNHA, J. SAN ROMÁN and R. L. REIS, J. Mater. Sci. Mat. Med. 14 (2003) 187.
29. CHeE-CHAN WANG and GING-HO HSIUE, J. Polym. Sci. Part A: Polym. Chem. 31 (1993) 1307

30. M. I. ABDEL-HAMID, K. S. KHAIROU and R. M. H A S S A N, J. Eur. Polym. 39 (2003) 381.

31. V. D. ATHAWALE and V. Lele, Carbohydr. Polym. 35 (1998) 21.

32. Idem., ibid. 41 (2000) 407.

33. R. L. WHISTLER, J. N. BEMILLER and E. F. PASCHALL, "Starch" (Accademic press, Inc., San Diego, 1984).

34. M. A. ARAUJO, C. M. VAZ, A. M. CUNHA and M. MOT A, Polym. Degr. Stabil. 73 (2001) 237.

35. K. HATA, T. KOKUBO, T. NAKAMURA and T. YAmamuro, J. Amer. Ceram. Soc. 78 1049.

36. Y. OKАмОто and S. HIDAKA, J. Biomed. Mater. Res. 28 (1994) 1403.

37. I. B. LEONOR, A. ITO, K. ONUMA, N. KANZAKI and R. L. REIS, Biomaterials 24 (2003) 579.

Received 10 July 2003

and accepted 21 January 2004 